\title{
REGRESSION MODEL CHANGE OF NORMAL CONTACT FORCES IN HEXAGONAL IDLER HOUSING FOR PIPE CONVEYOR LOADED WITH TRANSPORTED MATERIAL
}

\author{
Vieroslav Molnár' ${ }^{1}$ Beáta Stehlíková ${ }^{1}$ \\ 1 Technical University of Kosice, Letna 9, 04200 Kosice, Slovak Republic, e-mail: vieroslav.molnar@tuke.sk; \\ beata.stehlikova@tuke.sk
}

Received: 2018.04.21

Accepted: 2018.05.15 Published: 2018.06.01

\begin{abstract}
Pipe conveyors make up important elements of ecological transport systems. They ensure the material is transported in the conveyor belt coiled to the shape of a pipe. Various stresses impact their most important component - the conveyor belt - straining it in both, the longitudinal and the transverse direction. This phenomenon arises in connection with the shape of the conveyor route of the pipe conveyor, the width and thickness of the conveyor belt, the volume of the material conveyed, and the like. In recent years, more and more authors have been researching contact dependencies of the normal forces acting on the idler rolls located in idler housings. Their task is to design such structure of a conveyor belt that will put the least strain on the idler rolls, thus significantly reducing the power required to ensure the movement of the pipe conveyor. In this way, greater efficiency of eco-friendly transport will be achieved. Following experimental research, the paper describes a regression model of dependencies of normal contact forces on tension forces required, as per individual idler rolls in idler housing.
\end{abstract}

Keywords: contact forces, pipe conveyor belt, idler rolls, tension, release.

\section{INTRODUCTION}

Increasing demands on the transport of bulk materials require continual belt transport to be affected over longer distances and more diverse transport routes [1]. The pipe conveyor is a new type of special belt conveyor and it is employed in transport of bulk materials and raw minerals. Pipe conveyor is a modern means of solving the transport issues of problem-posing materials with adverse effects on the environment [2]. Main parameters of the pipe conveyor are calculated differently compared to the conventional belt conveyor parameters [3, 4]. Zamiralova and Lodewijks [5] presented a detailed procedure for calculating the rolling resistance of the conveyor belt of the pipe conveyor during its installation (insertion). Attention is paid to determining the magnitude of normal contact forces as well as that of the concentrated forces impacting each idler rolls of idler housing. Load forces depend on the weight of the transported material, the degree to which the pipe is filled with it, and the mass and stiffness of the belt. The viscoelastic behavior of natural rubber in the belt is modeled as a three-dimensional generalized model with multiple Maxwell parameters incorporated into a Winkler foundation. The same authors [6] also presented an experimental study examining the impact of the main pipe parameters such as pipe diameter, belt width, transverse bending stiffness, pipe weight, and belt overlapping position on load distribution over individual idler rolls, as well as the ability of the belt to form a stable pipe. Measurements were made using a static six-point device for testing the stiffness of the belt pipe XXX. The results they obtained have con- 
firmed that larger pipe diameters require greater bending stiffness in order for the conveyor belt to form a stable pipeline. The authors conclude that the pipe diameter can be varied either by varying the length of the overlap or by selecting a different width of the belt and by maintaining a constant pipe diameter - belt width ratio. In order to achieve stable form of the pipeline, more flexible belts require a larger overlap. If the width-to-pipe diameter ratio is constant for all belt widths produced, broader belts require greater stiffness.

Ivančo and Fedorko [7] investigated the issue of the impact of contact forces on idler rolls on a conventional belt conveyor using FEM analysis. Pang and Lodewijks [8] used FEM analysis to compare experimental results, obtained from an experimental device, to the pipe obtained from pipe conveyor's conveyor belt simulation, which provided the basis for drafting pipe conveyor design standards. Marasová et al. [9] analyzed the FEM model created in the Simulia-Abaqus program, the results of which served as a basis for research into conveyor belt dynamic wear. Fedorko et al. [10] drew on this research by starting to use a new experimental analysis of the conveyor belt inner structure, namely computerized tomography. $\mathrm{He}$ demonstrated a change in physical and mechanical properties of dynamically damaged conveyor belts and analyzed their inner structure using a nondestructive method of analysis - metrotomography. Similar research is also solved by $[11,12,13]$.

\section{METHODOLOGY}

During its operation, the pipe conveyor's conveyor belt is impacted by various resistances to movement that pose an impediment to this move-

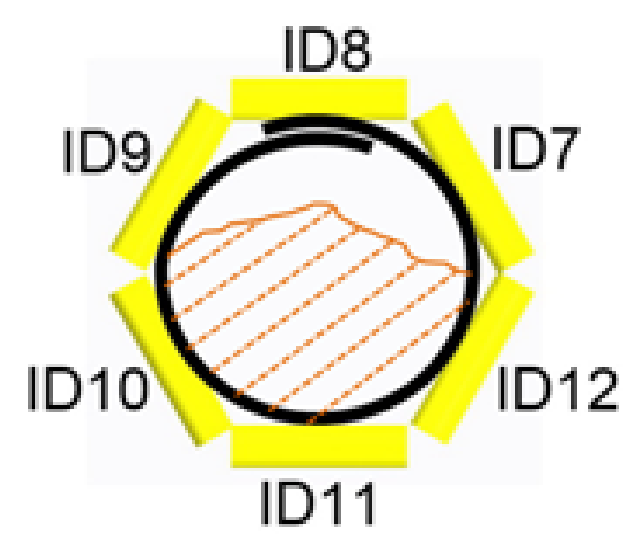

Fig. 1. A cross-section of the conveyor belt's crosssection filled with material, with idler rolls positions

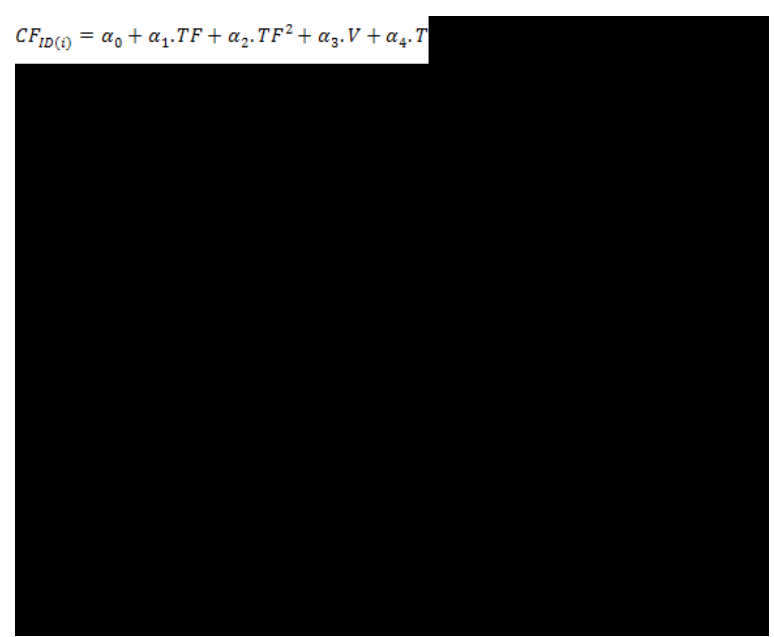

Fig. 2. Stand for measuring the normal contact forces of a coiled conveyor belt filled with material in static mode

ment. These resistances need to be minimized in order to reduce the power required for the pipe conveyor's efficient operation. However, it is very difficult to measure them under real conditions. This paper describes the measurements taken of normal contact forces $\mathrm{CF}$, impacting the idler rolls ID7 $\div$ ID11 (Figure 1) by effect of transverse stiffness of the coiled conveyor belt loaded with the material, under the belt's tensioning and releasing the desired tension force TF.

Consequently, regression models for individual idler rolls were designed and verified. Measurements were performed on a stand [14] designed specifically for the given purpose, in which an 8-m long coiled piece of conveyor belt was clamped, see Figure 2. Contact forces CF were measured by strain gauge sensors and their sequences were logged by a measuring apparatus, see [14]

\section{REGRESSION MODEL}

To estimate the pressure forces acting on idler rolls ID7 $\div$ ID12, we decided to factor in the following:

$\mathrm{TF}$ - the magnitude of the tensioning force,

$\mathrm{V}$ - the conveyor belt volume, filled with the material, defined as a share of the whole,

$\mathrm{T}$ - process type, this gives an account of whether an increase or decrease in TF is established as part of the TF change.

To model the CF change effect depending on the change in $\mathrm{TF}$, the following is factored in:

- linear member $\alpha_{1}$, for TF

- a quadratic member $\alpha_{2}$ for $\mathrm{TF}^{2}$. 


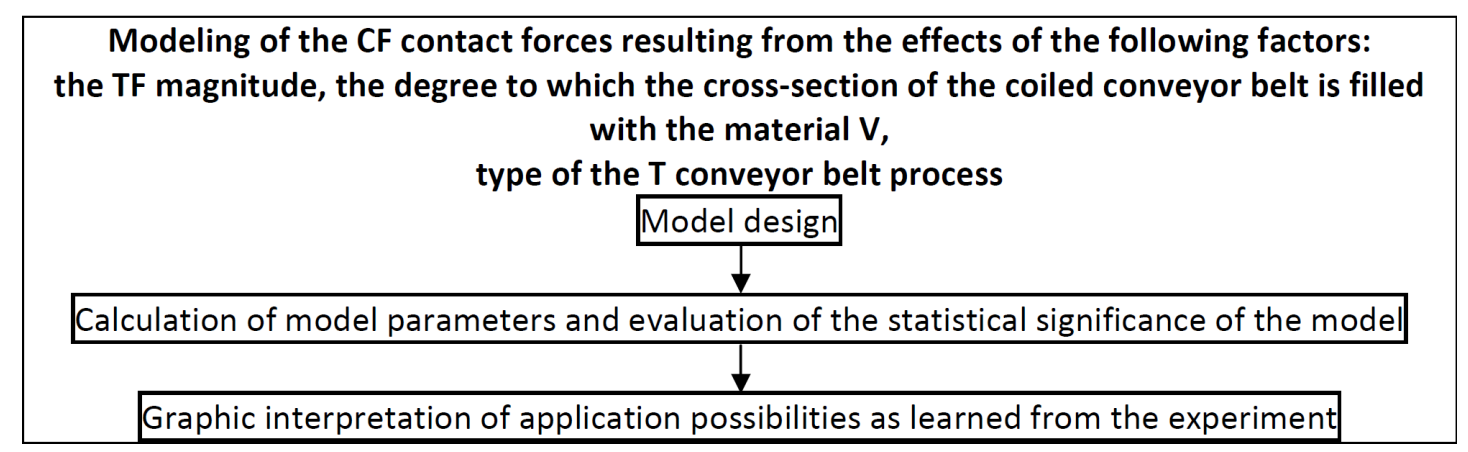

Fig. 3. Block diagram of the modeling process

For TF values, values established for the factor and the validity of the estimate lie between $4000 \mathrm{~N}$ and $28000 \mathrm{~N}$.

As for the V Factor - the volume of the conveyor belt filled with material, a linear dependence is considered. The estimated regressor is $\alpha_{3}$. The estimate for $\mathrm{V}$ values is valid in the range between 0 and 0.75 .

The effect of the type of the conveyor belt $\mathrm{T}$ process, with the tension and release options, is represented by the regressor $\alpha_{4}$. For the conveyor belt tension mode $\mathrm{T}=1$ and for the conveyor belt release mode $\mathrm{T}=-1$.

Based on these assumptions, the following form of a regression model was used:

$$
\mathrm{CF}_{\mathrm{ID(i)}}=\alpha_{0}+\alpha_{1} \cdot \mathrm{TF}+\alpha_{2} \mathrm{TF}^{2}+\alpha_{3} \cdot \mathrm{V}+\alpha_{4} \cdot \mathrm{T}
$$

where: $\mathrm{CF}_{\mathrm{ID(i)}}-$ contact force $\mathrm{CF}$ on the $\mathrm{i}$-th position of the idler roll, TF - tension force, $\mathrm{V}$ - volume in percentage, to which the cross section of the coiled conveyor belt is filled with the material, $\mathrm{T}$ - type of conveyor belt process that can be either tensioning or release, $\alpha_{0}, \alpha_{1}, \alpha_{2}, \alpha_{3} \alpha_{4}$ - are the estimated values of regressors for individual members.

Block diagram of the modeling process is in Figure 3.

\section{CALCULATION OF MODEL PARAMETERS AND EVALUATION OF THE STATISTICAL SIGNIFICANCE OF THE MODEL}

Calculation of model parameters and evaluation of statistical significance of the calculated regressors $\alpha_{0}, \alpha_{1}, \alpha_{2}, \alpha_{3}, \alpha_{4}$ is in Table 1 . To assess the significance of all model parameters, a significance level of 0.05 was chosen.

For each idler rolls position (ID7 $\div$ ID12) on the measured idler house, the regression values for the default model were calculated. For each regressor, the test criterion of statistical significance of the regressor $t$ was established, and so was its $p$ value. The $p$ value of each regressor (except for $\alpha_{0}$ ) was compared to the degree of significance. If the $\mathrm{p}$ value was less than 0.05 , the model was left as proposed. If the $\mathrm{p}$ value of any of the regressors was greater than 0.05 , the regressor was removed from the model, and all other parameters were re-calculated along with other test statistics, which are the $\mathrm{F}$ criterion of the regression function test and the Adjusted $\mathrm{R}$ squared value. The new model has a corr index in Table 1.

The $t$ value is the test statistics of the regressor significance and the $p$ value expresses the statistical significance of the regressor.

The F criterion expresses the adequacy of the regression equation - model used. Table 1 also shows its value and the $\mathrm{p}$ value. If the $\mathrm{F}$ criterion is high and the $p$ value is low, it means that the regression function describes the relationship between the inputs and the outputs well.

$R$ squared adjusted expresses the share of measurement results, expressed by the model. A high value, above 0.9 , indicates the model's adequacy.

\section{Regressor ranking for individual idler rolls ID7 to ID12 positions}

In addition to calculating the regressors and verifying their statistical significance, regressor values can be used to explain the behavior of the belt system's pressure forces on the idler housing, depending on the individual influences factored in.

Regressor $\alpha_{1}$ for TF is statistically significant in all positions and expresses the magnitude of the angle of graphic course of linear dependence.

Regressor $\alpha_{2}$ - a small negative value is logged for $\mathrm{TF}^{2}$ in all positions. For idler roll position ID11, regressor $\alpha_{2}$ is statistically insignificant. Its 
Table 1. Regressors for individual idler rolls positions ID7 $\div$ ID12

\begin{tabular}{|c|c|c|c|c|c|}
\hline Position of idler roll & ID7 & ID7 corr $_{\text {r }}$ & ID8 & ID9 & ID9 $9_{\text {corr }}$ \\
\hline$\alpha_{0}$ & 4.64 & 5.46 & 3.5 & 9.29 & $7: 33$ \\
\hline t statistics & 0.942 & 1.17 & 1.695 & 1.244 & 1.016 \\
\hline$p$ value & 0.3613 & 0.2593 & 0.1108 & 0.23272 & 0.32469 \\
\hline$\alpha_{1}(T F)$ & 0.005 & 0.005 & 0.002 & 0.007 & 0.007 \\
\hline t statistics & 7.288 & 7.425 & 7.342 & 6.61 & 6.606 \\
\hline$p$ value & $2.66 \mathrm{E}-06$ & $1.44 \mathrm{E}-06$ & $2.44 \mathrm{E}-06$ & $8.29 \mathrm{E}-06$ & 6.04E-06 \\
\hline$\alpha_{2}\left(T^{2}\right)$ & $-5.48 \mathrm{E}-08$ & $-5.48 \mathrm{E}-08$ & $-2.19 \mathrm{E}-08$ & $-9.64 \mathrm{E}-08$ & $-9.64 \mathrm{E}-08$ \\
\hline t statistics & -2.588 & -2.673 & -2.461 & -3 & -2.998 \\
\hline$p$ value & 0.0206 & 0.0179 & 0.0265 & 0.00897 & 0.00851 \\
\hline$\alpha_{3}(V)$ & 2.19 & & -8.07 & -5.21 & \\
\hline t statistics & 0.645 & & -5.647 & -1.01 & \\
\hline$p$ value & 0.5289 & & 4.64E-05 & 0.32873 & \\
\hline$\alpha_{4}(T)$ & -9.8 & -9.8 & 4.483 & -12.78 & -12.78 \\
\hline t statistics & -7.682 & -7.826 & -8.366 & -6.606 & -6.602 \\
\hline$p$ value & $1.41 \mathrm{E}-06$ & 7.37E-07 & 4.94E-07 & 8.35E-06 & $6.08 \mathrm{E}-06$ \\
\hline F statistics & 137.4 & 189.6 & 157 & 85.7 & 113.7 \\
\hline$p$ value & 1.27E-11 & $1.02 \mathrm{E}-12$ & 4.77E-12 & $3.83 \mathrm{E}-10$ & $5.31 \mathrm{E}-11$ \\
\hline Adjusted R-squared & 0.9663 & 0.9676 & 0.9705 & 0.9469 & 0.9468 \\
\hline Position of idler roll & ID10 & ID11 & ID11 ${ }_{\text {corr }}$ & ID12 & ID12 \\
\hline$\alpha_{0}$ & -48.3 & -31.8 & -7.02 & -55.9 & -49.4 \\
\hline t statistics & -2.668 & -1.2 & -0.645 & -3.687 & -3.205 \\
\hline$p$ value & 0.01756 & 0.074103 & 0.52819 & 0.002195 & 0.00552 \\
\hline$\alpha_{1}(T F)$ & 0.014 & 0.010 & 0.006 & 0.017 & 0.017 \\
\hline t statistics & 5.594 & 4.358 & 10.773 & 7.832 & 7.439 \\
\hline$p$ value & $5.12 \mathrm{E}-05$ & 5.63E-04 & 9.66E-09 & $1.12 \mathrm{E}-06$ & $1.41 \mathrm{E}-06$ \\
\hline$\alpha_{2}\left(T F^{2}\right)$ & $-2.08 \mathrm{E}-7$ & $-1.34 \mathrm{E}-07$ & 0.00 & $-2.60 E-07$ & $-2.60 \mathrm{E}-07$ \\
\hline t statistics & -2.688 & -1.889 & & -3.994 & -3.794 \\
\hline$p$ value & 0.01756 & 0.078389 & & 0.001174 & 0.001594 \\
\hline$\alpha_{3}(V)$ & 41.69 & 103.7 & 103.7 & 17.32 & 0.00 \\
\hline t statistics & 3.332 & 9.073 & 8.422 & 1.653 & \\
\hline$p$ value & 0.00455 & 1.77E-07 & $.283 \mathrm{E}-07$ & 0.119029 & \\
\hline$\alpha_{4}(T)$ & 16.97 & 15.04 & 15.04 & 16.72 & 16.72 \\
\hline t statistics & 3.617 & 3.509 & 3.258 & 4.257 & 4.043 \\
\hline$p$ value & 0.00254 & 0.003163 & 0.00494 & 0.000689 & $9.42 \mathrm{E}-04$ \\
\hline F statistics & 55.46 & 58.22 & 65.86 & 91.62 & 109.4 \\
\hline$p$ value & 8.26E-09 & 5.88E-09 & $3.20 \mathrm{E}-09$ & $2.36 \mathrm{E}-10$ & $7.13 \mathrm{E}-11$ \\
\hline Adjusted R-squared & 0.9198 & 0.9233 & 0.911 & 0.9502 & 0.9448 \\
\hline
\end{tabular}

meaning lies in the curvature of the function for calculating the $\mathrm{CF}$ contact force downwards, its sign is negative.

Regressor $\alpha_{3}$ for the degree to which the cross-section of the coiled conveyor belt is filled with the material $\mathrm{V}$ is statistically insignificant in idler rolls ID7, ID9 and ID12 positions. Positive sign of the regressor $\alpha_{3}$ in idler roll positions ID7, ID10, ID11, ID12 indicates that the degree to which the cross-section of the coiled conveyor belt is filled with the material $\mathrm{V}$ increases the $\mathrm{CF}$ value of the contact force. The negative sign of regressor $\alpha$ in idler rolls positions ID8 and ID9 indicates that the degree to which the cross-section of the coiled conveyor belt is filled with the material $\mathrm{V}$ reduces the contact force $\mathrm{CF}$.

Regressor $\alpha_{4}$ for $\mathrm{T}$ (type of conveyor belt process) is statistically significant in all positions. 

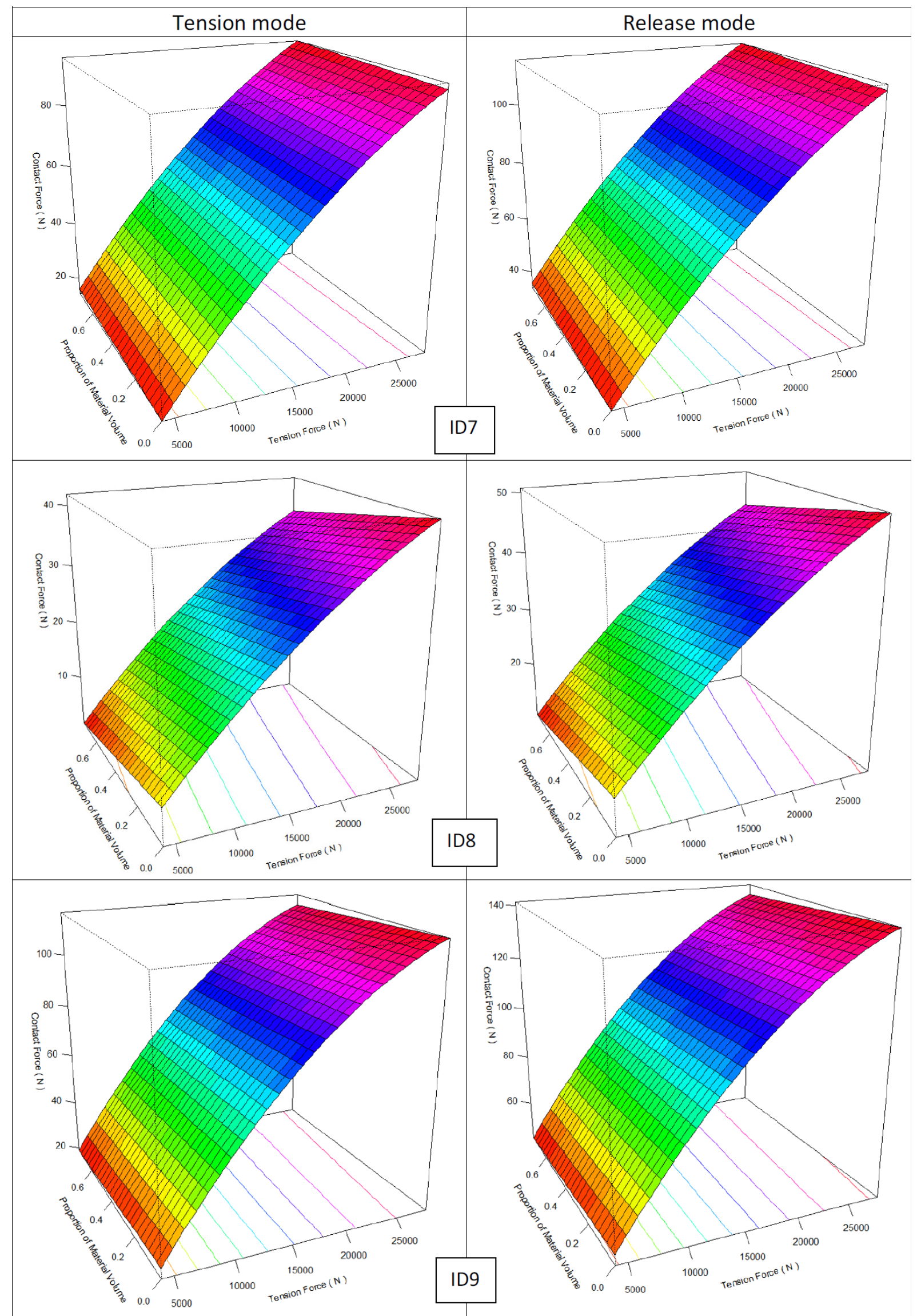

Figure 4. Graphical interpretation of designed regression models for idler rolls ID7 $\div$ ID9 


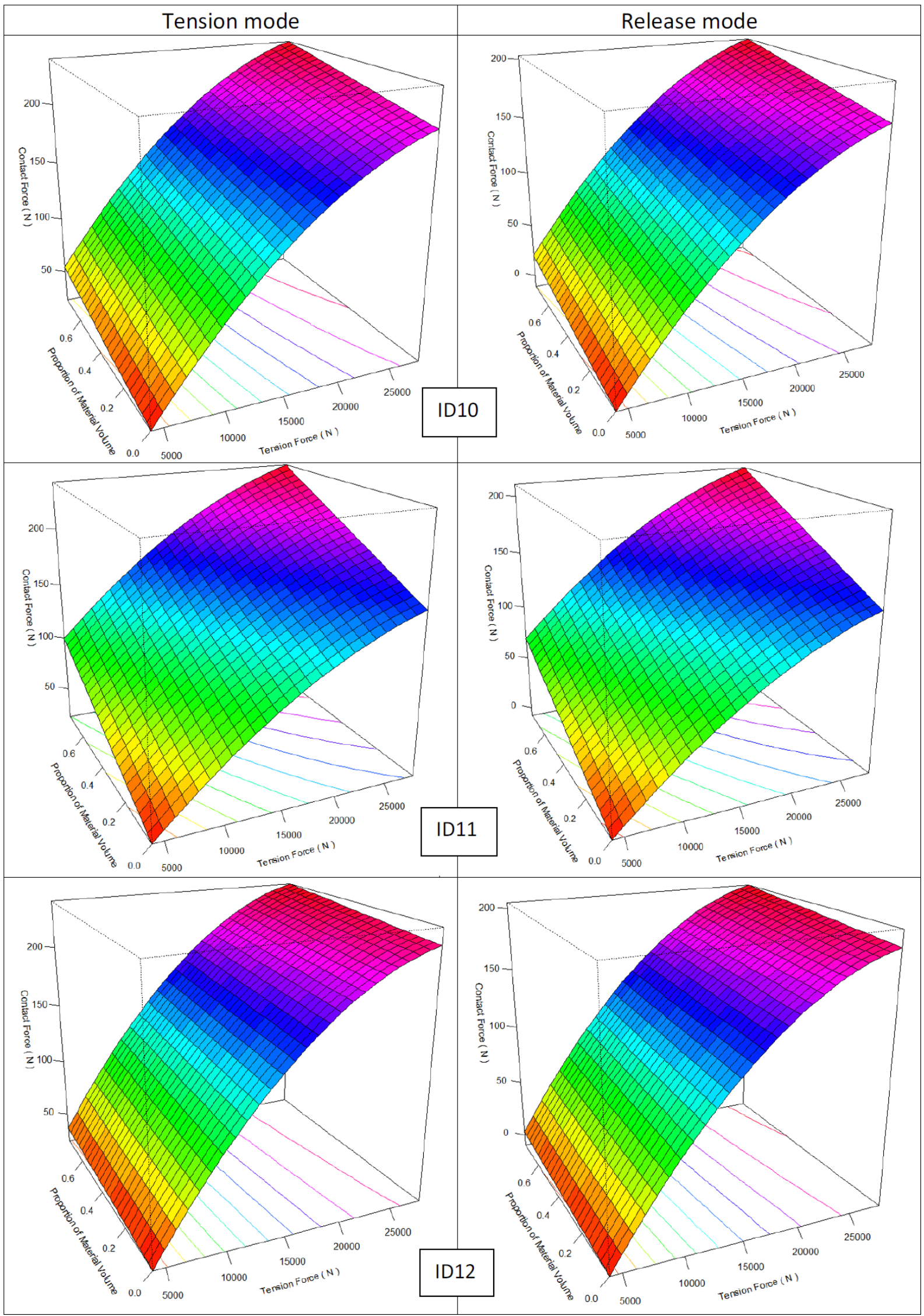

Fig. 5. Graphical interpretation of designed regression models for idler rolls ID10 $\div$ ID12 
From the practical point of view, it can be stated that if $\mathrm{T}$ acquires the value " 1 ", idler rolls positions ID7, ID8 and ID9 with negative regressor $\alpha_{4}$ reduce the $\mathrm{CF}$ value of the contact force. If $\mathrm{T}$ acquires the value of "-1", the idler rolls positions ID10, ID11 and ID12 with positive regressor $\alpha_{4}$ increase the $\mathrm{CF}$ value of the contact force.

\section{Adequacy assessment of the regression function for individual idler rolls positions ID7 to ID12}

The value of the $\mathrm{F}$ criterion for assessing the regression function is statistically significant for all positions. For modified models with a corr index, the F criterion value is higher in all cases compared to the original models. The selected regression function is adequate in all cases.

The criterion for assessing the adequacy of the regression function Adjusted R squared reflects the share of variability in the original data as described by the model. For all idler rolls positions and calculated models, that value is higher than 0.9. This means that the models describe more than $90 \%$ of the variability of the originally measured data.

For models with corr index, the drop in the Adjusted R squared value is very small, that is, by removing the regressor, the share of the described variability has decreased only marginally.

\section{GRAPHIC INTERPRETATION OF APPLICATION POSSIBILITIES AS LEARNED FROM THE EXPERIMENT}

Figure 4 and Figure 5 show that for all idler rolls positions ID7 $\div$ ID12, the main CF change factor is the change factor TF. For idler roll ID11, it can be observed that it is most affected by the change in $\mathrm{V}$ - the volume to which the conveyor belt is filled with the material conveyed.

Tension or Release mode affects the CF value. For Release mode, the CF value is higher for the same TF and V values in idler rolls ID7, ID8 and ID9 positions. For other idler rolls (ID10, ID11 and ID12) positions, the Release mode value CF is lower.

\section{CONCLUSION}

From the values of regressors obtained for individual idler rolls positions, it is possible to explain the behavior of the most important ele- ment of the ecological transport system of the pipe conveyor - the conveyor belt, dependent on the degree to which it is filled with the conveyed material and the way it is operated.

The obtained results can be used in further research to test other types of conveyor belts to create a database of models for different conveyor belts of pipe conveyors to provide users and designers with new insights into the field of measuring, evaluating and designing new types of pipe conveyor belts.

\section{ACKNOWLEDGMENTS}

This article was elaborated in the framework of the Grant Projects VEGA 1/0403/18, VEGA 1/0063/16, KEGA 018TUKE-4/2016.

\section{REFERENCES}

1. Alspaugh M.A. Latest Developments in Belt Conveyor Technology. Proc. of MINExpo 2004, 2004.

2. Holt P. Enclosed bulk transport - Tubular/pipe belt conveyor. Bulk Solids Handl., 21, 2001, 347-349.

3. Zhang Z.Z.Z., Zhou F.Z.F. and Ji J.J.J. Parameters calculation and structure design of pipe belt conveyer. Proc. of 9th Int. Conf. Comput. Ind. Des. Concept. Des., 2008.

4. Marasová D., Fedorko G. and Molnár V. Hadicový dopravník a výpočet jeho základných parametrov. Acta Montan. Slovaca, 7, 2002, 101-107.

5. Zamiralova M.E. and Lodewijks G. Energy Consumption of Pipe Belt Conveyors: Indentation Rolling Resistance. Transactions_FME, 40, 2012, 171-176.

6. Zamiralova M.E. and Lodewijks G. Measurement of a pipe belt conveyor contact forces and cross section deformation by means of the six-point pipe belt stiffness testing device. Measurement, 70, 2015, 232-246.

7. Ivančo V. and Fedorko G. Analysis of Force Ratios in Conveyor Belt of Classic Belt Conveyor. Procedia Eng., 48, 2012, 123-128.

8. Pang Y. and Lodewijks G. Pipe belt conveyor statics - Comparison of simulation results and measurements. Bulk Solids Handl., 33, 2013, 52-56.

9. Marasova D., Fedorko G., Kubin K., Molnar V. and Husakova N. Analysis model for determination of contact loads between tube-shaped conveyor belt of a pipe conveyor and carrier rolls. Cuprum Czas. Nauk. Górnictwa Rud., 3, 2010, $71-76$.

10. Fedorko G., Molnár V., Živčák J., Dovica M. and Husáková N. Failure analysis of textile rubber conveyor belt damaged by dynamic wear. Eng. Fail. Anal., 28, 2013, 103-114. 
11. Rudawska A. and Debski H. Experimental and numerical analysis of adhesively bonded aluminium alloy sheets joints. Eksploatacja i Niezawodnosc Maintenace and Reliability, 1, 2011, 4-10.

12. Jachowicz T., Sikora R. Methods of forecasting of the changes of polymeric products properties. Polimery, 51 (3), 2006, 177-185.
13. Fedorko G., Beluško M. and Hegedüš M. FEA utilization for study of the conveyor belts properties in the context of internal logistics systems. Proc. of CLC 2015 Carpathian Logist. Congr., 2016, 293-299.

14. Michalik P. and Zajac J. Using of computer integrated system for static tests of pipe conveyer belts. Proc. of 13th Int. Carpathian Control Conf. (ICCC), High Tatras, Slovakia 2012, 480-485. 